\title{
Evaluation of new knowledge generation in the oil and gas sector of Russia through the prism of patent activity
}

\author{
Valeriy Kryukov ${ }^{1}$, and Anatoliy Tokarev ${ }^{1, *}$ \\ ${ }^{1}$ Institute of Economics \& Industrial Engineering, 63009017 Ac. Lavrentiev Av., Novosibirsk, Russia
}

\begin{abstract}
One way to describe the evolution of the modern knowledge base in the Russian oil and gas sector (OGS) is to consider it through the dynamics and results of patent activity related to inventions. On the whole, we observe rising complexity of the industrial knowledge base of OGS, which responds to changes in the resource base of OGS and reflects worldwide trends of innovation-driven growth. Notably, Russian inventions for OGS comprise rather limited use of technologies from complementary knowledge fields.
\end{abstract}

\section{Introduction}

At present, both globally and in Russia, the oil and gas sector (OGS including geological prospecting, exploration, and extraction - "upstream") faces significant complication in conditions of hydrocarbon resources development - the state, which requires elaboration and widespread use of new science-intensive technologies and solutions. It should be noted that Russian OGS is producing very little innovative technologies today. Thus, over the period of 2010-2018 the whole mineral resource sector (including OGS) produced just 12 new technologies that have no foreign countertypes. At the same time, there are very many innovative technologies in use to imply that most of them are of foreign origin. This state of things raises serious risks for future development of Russian OGS (especially with volatile and low prices).

It is vitally important to intensify significantly the innovative activity in Russia's OGS. It should be noted that foreign countries now have an explosive growth in the patent activity. Thus, in the 2000 -s, the number of patent claims concerning technologies of shale oil and gas extraction grew exponentially.

The current state of the resource base of OGS dictates the necessity of escalating innovative activity relative to mature oil and gas fields and to new promising provinces as well. This necessity is greatly augmented by unstable oil prices and sanction pressure on Russia's OGS, which is focused on high tech extraction - sea shelf projects and development of hard-to-recover reserves.

\footnotetext{
*Corresponding author: anatoli-3@yandex.ru
} 


\section{Materials and methods}

In this day and age, knowledge is one of the key factors of long-term economic development. Lately, researchers have been paying more attention to analyzing innovation processes relative to industries, regions and companies. Such analysis allows elaborating more reasoned recommendations and development strategies as applied to respective facilities including OGS.

Analysis and study of innovative processes in OGS embraces a wide range of problems including:

- the role of new technologies in development of OGS, their impact on costs and resource reclaiming dynamics [1];

- effect of oil price level on innovative processes [2];

- patent activity dynamics [3];

- institutional questions of innovation policy [4];

- spatial aspects of new knowledge generation in OGS [5].

An important direction of analysis into innovative processes in OGS is the study of processes that take place in the field of patenting inventions [6]. E.g. technologies in oil and gas industries are structured based on patent documents [7]. Another important aspect of patent issues in OGS is analysis of resource base evolution and its impact on patent activity. E.g. it is important to answer the question: in what way discovery of new difficult resources influences the policy of their reclamation participants in the area of patenting their engineering research [8].

In the present context, coordination of innovative activity in OGS became the line of responsibility for mostly high tech companies from countries with developed economies. The majority of them are large oilfield service companies that carry out large volumes of research and development [9]. This situation is part of mainstream trends of global technological development relative to emergent international networks that create new technologies and manage the entire process. Major international companies use their capacity of extracting benefits from a geographically distributed portfolio of new knowledge sources [10]. Thus, one of the largest oil field service companies - Halliburton has over 55 thousand staff working in over 80 countries. The company provides services throughout the entire life cycle of development of oil and gas fields. The organizational structure of multinational corporations operational in several countries is highly effective in obtaining and aggregating knowledge from all over the world [11].

One of the approaches to analyzing innovative processes presumes that new knowledge arises through recombination (new combination) of disparate fragments of existing knowledge distributed among economic agents [12]. This being said, in current conditions, the knowledge bases of certain industries feature a high degree of dynamics. Their evolution (most notably, the speed and direction of change) depend on a number of factors and circumstances: new knowledge also appears in adjacent technological areas; the role of some established knowledge diminishes; new links come up between fields of knowledge that used to have none. The resulting dynamics changes the relative ratio between old and new knowledge and their links that may depend, for example, on a life cycle of key technologies or transformation of technological structure of an industry as a whole.

In a number of publications, industrial knowledge bases are reviewed in terms of technologies employed to generate new knowledge as patents for invention. Thus, this approach was used to evaluate the knowledge base of high tech industries (biotechnology and telecommunications) [13]. A knowledge base of a particular industry may be viewed as a network with nodes of quoted (in patent documents) subclasses of international patent classification (IPC) (technologies) and with ties between nodes as combinations of 
technological classes in one and the same patent. For this purpose, the generalized features of the knowledge base may embrace the following:

- a variety of technology combinations comprising the industrial knowledge base;

- coherence of technologies demonstrating how often technological subclasses combine in patent documents;

- cognitive distance that measures a degree of difference between technologies forming the industrial knowledge base [14].

From the perspective of this approach we analyzed the industrial knowledge base of OGS in Russia. This analysis involved inventions - a connecting link between the sphere of research and development, on the one hand, and development and application of new technologies, on the other. We used the database of the Federal institute of industrial property in reference to Russian invention synopses, in particular those published in the official bulletin of the Federal service for intellectual property "Inventions. Utility models". We have reviewed the 4-digit subclass IPC E21b "Ground or rock formations drilling; oil and gas extraction" that most completely illustrates the process of knowledge generation in OGS. This subclass is part of the larger section (macro-class) IPC "E - Construction and mining".

The dynamics of OGS knowledge base in Russia (as far as patents of invention are concerned) was analyzed in terms of several indicators:

- variety of used technologies estimated through information entropy at the level of macroclasses of IPC;

- probability of utilization in oil and gas patents of contiguous macro-classes and technologies, i.e. technologies outside the subclass E21b.

\section{Results and Discussion}

What areas of engineering and what kinds of technology are most frequently used for inventions in OGS? In line with the implemented approach, every patent under consideration employs the subclass IPC E21b. At the same time, one patent document may have indices of several technologies (subclasses from broader sections of IPC).

In the period under our consideration the patent documents of IPC were most likely to have section (macro-class) "C - Chemistry; metallurgy" (Figure). In 2017-2019, 13-14\% of reviewed inventions contained technologies of this section (in figure - Section of IPC "C"). Sections " $\mathrm{G}$ - Physics" and " $\mathrm{F}$ - Machine building; engines and pumps" have lower probability (about $8 \%$ ). On the whole, the probability of patent documents having technologies from contiguous sections (in figure - "Contiguous technologies") grew from $16-20 \%$ to $37-39 \%$ over the period from $2005-2007$ to $2017-2019$.

However, the share of patents with more than one subclass E21b is around $50-60 \%$. This means that industry-specific innovators rather seldom resort to knowledge and technologies from contiguous areas of engineering, i.e. outside the IPC section "E Construction and mining". This demonstrates that under current conditions in Russia's OGS innovators are mostly focused on incremental rather than radical innovations.

Among the subclasses of IPC, the key position among invention patents under review belongs to the subclass $\mathrm{C} 09 \mathrm{k}$ - Materials, that is, mostly compositions for drilling and treatment of wells (in figure - IPC subclass C09k). About $11-12 \%$ of synopses of all oil and gas patents published in 2017-2019 contained indices of this subclass. Here we observe a clear trend of this subclass growing: the probability of its inclusion in patents over the period of 2005-2019 grew by more than 7 times. Respectively, this subclass is the only growth driver of the whole " $\mathrm{C}$ " section. 


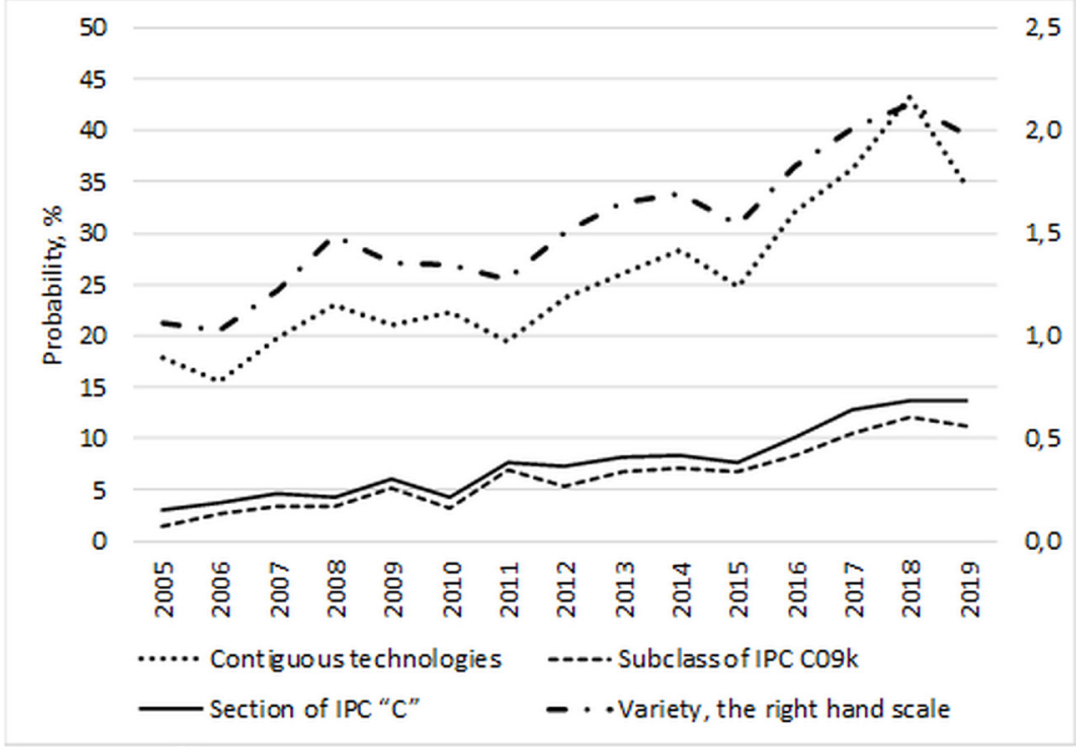

Fig. 1. The dynamics of indicators describing the OGS knowledge base (with respect to invention patents).

A large part of the contiguous subclass $(\mathrm{C} 09 \mathrm{k})$ is determined by a number of factors concerning peculiar features of the mineral resource base of Russia's OGS, current status of the innovation sphere in Russia and trends of OGS's global technological development. These factors include:

- development of drilling technologies, e.g. high tech horizontal wells with the aid of new drilling solutions;

- the need to cultivate wells at mature sites (employing new compositions);

- the necessity to produce new technologies for development of hard-to-reach deposits and raising oil recovery;

- wide use and development of technologies of hydraulic fracturing (requiring new compositions for its implementation).

At the same time (with a rather low level of indexing technologies from contiguous sections), domination of one subclass of IPC (C09k) reflects a one-sided development of patent activity as concerns the OGS. Very seldom one can see other subclasses related among other to oil and gas machine building, equipment manufacturing, and digitalization of oil and gas extraction. Thus, the probability of finding such (frequently used by Russian standards) subclasses of IPC as hydraulic machines of volume displacement, pumps and compressors (F04b); digital data processing (G06f); material analysis through determination of their chemical or physical properties (G01n) is only at the level of $1-2 \%$. This situation contains dire risks for technological development of the Russian OGS, above all in development of domestic technologies.

Technologies most frequently encountered in patents may serve as a guidemark to form technological alliances between companies and organizations that have sets of required competences in respective areas of expertise. Unfortunately, in contemporary Russian practice, companies rarely engage in joint research and development projects that becomes a restraining factor for development of new approaches and solutions.

Since 2005, a variety of OGS knowledge base has a tendency to grow (see the figure Variety). This trend is in many ways a result of growing probability that patents will use technologies from contiguous sections of IPC (beyond the boundaries of subclass E21b). The variety demonstrates a much similar dynamics with the common trend of rising 
probability of use of technologies from contiguous sections (repeating the same growth and some decline periods). To some extent, a certain fall of observed indicators in 2015 and 2019 stems from lower patent activity of foreign companies in Russia. This is due to the fact that their patent documents have higher variety of indexed technologies for they represent a broader range of contiguous technologies.

\section{Conclusion}

The place and role of OGS in Russia's economy as well as its complicating resource base demand the necessity of active innovative policy on behalf of resource companies. The dynamics of considered indicators that describe the industrial knowledge base of OGS on the whole demonstrate growing complexity. At the same time, Russian inventions are based on very limited use of technologies from contiguous areas of knowledge that casts doubts as to the possibility of domestically creating completely new breakthrough technologies.

Technological development of OGS that is up to contemporary challenges requires closer interaction of a wider range of innovation participants: oil production companies, oil and gas field service, scientific organizations, higher education establishments, machine building enterprises. Such joint efforts may become an important premise for more fruitful work in the area of innovation in OGS [15].

Growing complexity of conditions for development of oil and gas resources dictate the necessity of change in the whole system of regulation - licensing, taxation, scientifictechnical policy and regulation of monopolies. We need conditions and effective stimuli for putting OGS on innovative trajectory of development. One such approach may embrace wider use of technological testing grounds targeting generation of new knowledge and innovations resulting from interaction of companies and organizations with competencies in various technical areas.

\section{Acknowledgement}

The paper has been written with financial support of the Russian Science Foundation (grant \#19-18-00170).

\section{References}

1. H. Hassani, E. Silva, A. Kaabic, Technological Forecasting and Social Change, 119, 117 (2017)

2. B. Daniels, D. Johnson, Resources Policy, 64, 42-51 (2019)

3. J. Krafft, F. Quatraro \& P. Saviotti, The knowledge-base evolution in biotechnology: a social network analysis // Journal Economics of Innovation and New Technology, 20:5, 445-475 (2011)

4. S. Ghazinoory, M. Goodarzi, Technological Forecasting and Social Change, 122, 262274 (2017)

5. S. Hatakenaka, P.Westnes, M. Gjelsvik, R. Lester, International Journal of Innovation and Regional Development, 3:3, 305-323 (2011)

6. S.-C. Ma, L. Feng, Y. Yin, J. Wang, World Patent Information, 56, 29-38 (2019)

7. A. Deorsola, A. Rodrigues, C. Salerno, World Patent Information, 35:1, 42-51 (2013)

8. G. Cavalheiro, L. Joia, A. Gonçalves, World Patent Information, 39, 58-68 (2014) 
9. A. Maleki, A. Rosiello, Technological Forecasting and Social Change, 143, 273-288 (2019)

10. J. Cantwell, Journal of International Business Studies, 40, 35-41 (2009)

11. J. Mattes, Transnational Corporations and Transnational Governance, (Palgrave Macmillan, London, 2015)

12. J. Zhang, Y. Yan, J. Guan, Technological Forecasting and Social Change, 143, 260272 (2019)

13. J. Krafft, F. Quatraro, P. Saviotti, Industry and Innovation, 21:3, 215-242 (2014)

14. P. Saviotti, Structural Change and Economic Dynamics, 18, 387-408 (2007)

15. V. Kryukov, A. Tokarev, Regional Research of Russia, 8:3, 248-257 (2018) 